\title{
Fund Correction: Unrecognized Ruptured Intracranial Aneurysm Presenting as Cerebral Vasospasm-Induced Ischemic Stroke: A Case Report
}

Joong-Goo Kim, $\mathrm{MD}^{1}$, Chul-Hoo Kang, $\mathrm{MD}^{1}$, Jay Chol Choi, $\mathrm{MD}, \mathrm{PhD}^{1}$, Jong-Kook Rhim, MD, $\mathrm{PhD}^{2}$

${ }^{1}$ Department of Neurology, Jeju National University Hospital, Jeju National University School of Medicine, Jeju, Korea

${ }^{2}$ Department of Neurosurgery, Jeju National University Hospital, Jeju National University School of Medicine, Jeju, Korea

Correction to: Neurointervention https://doi.org/10.5469/neuroint.2021.00017, published on July, 2021, Neurointervention 2021;16:180-184.

In the originally published version of this article was missing content in the Fund section, which should be properly revised as follows:

\section{Before correction:}

Fund

None.

\section{After correction:}

Fund

This work was supported by a research grant from Jeju National University Hospital in 2017.

The authors apologize for any inconvenience that it may have caused.

\section{Correspondence to: Jong-Kook Rhim, MD, PhD}

Department of Neurosurgery, Jeju National University Hospital, Jeju National University School of Medicine, 15 Aran 13-gil, Jeju 63241, Korea Tel: +82-64-717-1620, Fax: +82-64-717-1630, E-mail: nsrhim@gmail.com 